\title{
EDITORIAL
}

\section{A new journal and new opportunities}

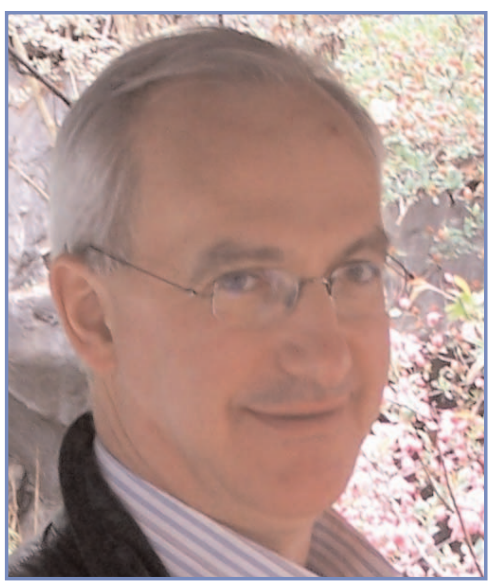

Laurence Klotz

Editor-in-Chief

CUAJ $\mathrm{t}$ is my great pleasure to introduce the first issue of our new journal, the Canadian Urological Association Journal (CUAJ), the only journal owned, operated and endorsed by the Canadian Urological Association (CUA).

You may know that I was the editor of the Canadian Journal of Urology $(C J U)$, which I founded in 1992, and served until late 2006. The CJU had been the official journal of the CUA since 1996. The journal made a substantial impact nationally and internationally. However, due to increasing challenges involving the publisher of the $C J U$, the CUA decided in June 2006 to discontinue this relationship. I resigned as editor soon after, as did the board of the CJU. The CUA was determined to produce its own journal, the CUAJ, and invited me to serve as editor-in-chief. Before I accepted the position, I had extensive discussions with the CUA, its Board of Directors, and the CUA president and past president about our mutual roles and responsibilities. I concluded that the aims and objectives of the CUA in initiating a new journal were very close to my own.

These are exciting times for the journal. We have a crackerjack managing editor, Josephine Sciortino, who was managing editor of the Canadian Medical Association Journal $(C M A)$ ), and is preternaturally talented and energetic. There is a great deal of high quality basic, clinical, and health services research taking place in our field nationally and internationally which should provide the basis for strong scientific publications. We have been in contact with the National Library of Congress administrators, and we are confident that indexation on PubMed, retroactive to the first issue, will be forthcoming within one to two years.

One of our main challenges is to encourage leading academic urologists and other clinicians to support this CUA initiative, and submit their highest quality research to CUAJ. In return, we will provide increased editorial assistance to authors and promise rapid manuscript turnaround. We will publish commentaries on certain review and research articles, theme-related supplements and point-counterpoint articles to highlight controversies in urology. We will also publish abstracts from the CUA, Northeastern section of the AUA, and QUA meetings. Our editorial board is a broad representation of specialists from training centres across the country, as well as clinicians and researchers from outside urology. We have also established a team of 100 reviewers who are committed to timely and high-quality appraisal of manuscripts. In addition, we plan to increase our content for French-speaking readers. Finally, we will be posting the complete issue online and are working toward an online submission and peer-review process.

Urology and our health care system are both in a state of transition and face many challenges. CUAJ will continue to provide an opportunity for discussion of scope of practice, privatization, health care funding, wait times, screening, and other public policy related questions.

CUAJ welcomes feedback from readers. I and the members of the CUAJ board will be happy to discuss the progress and vision of the journal with you in person at national and regional conferences. This is your journal. Help us build it, for the benefit of our Canadian urology community today and Canadian urologists of the future. 